\title{
Covid-19: Doctors sound alarm over hospital transmissions
}

\author{
With the pandemic continuing, the risk of hospital acquired infection is worrying doctors, Gareth \\ lacobucci finds
}

Gareth lacobucci

The BMJ

Doctors have told The BMJ they are deeply concerned at the number of patients becoming infected with covid-19 in NHS hospitals in England and have called for more stringent infection control measures to combat its spread.

They cite limited capacity for testing and retesting as a barrier to keeping covid and non-covid patients separated in so called "green" and "red" zones. There also have concerns about the availability of side rooms and cubicles to keep patients separate and believe that poor ventilation in areas other than intensive care units may be contributing to nosocomial infections.

Jan Coebergh, a consultant neurologist in Surrey who has worked on covid wards at several sites since the outbreak began, told The BMJ that he had seen distressing cases of patients becoming infected with the virus from other patients while in hospital and who were likely to die as a result.

"There clearly is intra-hospital patient transmission," he said. "In intensive care and the respiratory wards they have special ventilation. But the other mixed wards with people awaiting swab results don't have very good ventilation, and so I think they are kind of dangerous places."

Coebergh called for more aggressive, timely, and regular testing of all hospital patients and for stricter separation to reduce the risk of infection spreading.

"We need to separate patients as much as possible with physical distancing or single rooms for people awaiting swab results," he said. "And then it's about ventilation and testing. We need to test all inpatients every week to start tracking whether super-spreading events occur in hospitals."

Tullie Yeghen, a consultant haematologist in south London, said she had seen cases of vulnerable haematology patients who had died as a result of nosocomial transmission of covid-19 in hospital. She believes the infection was contracted either on a designated green ward for non-covid patients or after admission to a "covid suspected" cohort bay pending swab results.

In a rapid response to The $B M J$ this week Yeghen called for extra measures to protect patients. ${ }^{1}$ She wrote, "Securing the safety of our vulnerable patients would require, as a minimum, the allocation of all shielded patients to a side room in the appropriate colour coded ward pending SARS-CoV-2 status, given the difficulty in making or excluding the diagnosis clinically and the potentially devastating consequences of nosocomial transmission. A more rapid turnaround time for tests would greatly facilitate this process.

"In addition, allocation to green areas of staff less likely to transmit SARS-CoV-2 needs urgent consideration and back up by national recommendations. Finally, urgent consideration is needed for the provision of additional side rooms and isolation facilities in centres treating patients with covid-19."

\section{No official data}

Currently there are no official figures on numbers of patients contracting covid-19 in hospitals. However, the Guardian newspaper reported that the proportion of covid-19 infections acquired in hospital was between $10 \%$ and $20 \%$, although NHS sources told the paper that the figures were skewed by poor infection control procedures at one single trust and that the true rate was lower, at around $5 \%$ to $7 \%{ }^{2}$

Although the government loosened lockdown controls last week, the prime minister admitted in parliament that further progress would not be possible "unless we crack these twin epidemics both in care homes and in the NHS."

Coebergh said data on hospital acquired covid-19 needed to be made readily available to ensure that patients weren't put off seeking care in acute settings. "Unless we have the data, we can't reassure patients and say, 'We have done this and this and to reduce it," he said. "We have a duty to tell people if they've been possibly harmed by our care."

The International Severe Acute Respiratory and Emerging Infection Consortium is looking at data from around a third of hospital trusts in England to try to assess the level of hospital acquired infection connected to covid-19.

Chris Green, senior clinical lecturer and consultant physician in infectious disease at University of Birmingham and an investigator with the consortium, said it was appropriate for each trust to tailor its infection control to local circumstances, noting that larger hospitals may be able to set up separate "hot" and "cold" sites for covid and non-covid patients, while smaller 
hospitals may have to settle for internal "hot and cold pathways" within one site.

"Getting it right will not be a black and white measure. Some trusts will probably manage better than others, but then some are in a better position than others to get it right in the first place, depending on how they are set up and the local epidemiology," he said.

But Green emphasised that every hospital should be separating patients into three groups to minimise the spread of infection: patients with confirmed covid-19, patients confirmed not to have it, and those in whom it is suspected but not confirmed.

"The only thing that we can do now-as well as social distancing-is to carry on with these blunt measures, like separating 'hot' hospitals from 'cold' hospitals (or hot zones from cold zones within hospitals), and aggressively testing staff and patients whenever we can to try to pick out as early as possible who is PCR [polymerase chain reaction] positive and isolate [them]. That'll be the only way that we can really get the hospital transmission down further."

But he added, "Of course, you have to be realistic. There will always be some transmission, not least because transmission can occur in asymptomatic people. But there is also a significant false negative rate from nasopharyngeal swabs taken in the early stages of infection."

More broadly, Green said that the risks of nosocomial transmission needed to be balanced with the risk of a patient not being treated in hospital at all. "Now that we're coming down the peak ... there is a risk of hospital acquired infections, but also there is a significant risk of harm coming to you if you don't have access to hospital care," he said.

\section{Avoiding overcrowding}

The importance of infection control will come into sharper focus as the NHS begins to restart many other services that were stopped during the pandemic and as people who may have been seeking care elsewhere, or not at all, return to hospitals.

Katherine Henderson, president of the Royal College of Emergency Medicine, said it was vital that emergency departments did not return to the chronic overcrowding and "corridor care" of times before the pandemic, as this would make nosocomial infection far more likely.

She said, "We cannot restart emergency departments at the same level that they were at before and end up with crowded departments. But that means quite a lot of reorganisation. We can't offload ambulances into a corridor any more. How do we do social distancing? How do we make sure we've got enough cubicles? All emergency departments in the land are wondering what to do about this. There's a lot of fast footwork needed, because patients are beginning to come back."
Henderson said the whole health and care system needed to cooperate to ensure that emergency departments were safe places for patients with genuine emergencies.

"Emergency departments can't be a safety net for a lot of lower acuity clinical presentations that perhaps other parts of the system should be managing," she said. "We've got to think very carefully about who comes to the emergency department and why, so that we're seeing the right people and keeping the most vulnerable safe.

"If someone has been shielding at home, and then they happen to get chest pain or fall over and break their hip, it cannot be that it's a bad thing for them to come into the emergency department."

\section{Stopping infection by staff}

Testing of staff is just as important as testing patients, particularly given the well publicised problems with staff lacking personal protective equipment. Las week ( 11 May) a study by University of Cambridge researchers found that hospital staff may be carrying SARS-CoV-2 without realising it. ${ }^{4}$ Researchers swabbed and tested more than 1200 NHS staff at Addenbrooke's Hospital in Cambridge throughout April. Of more than 1000 staff reporting fit for duty, 3\% tested positive for the coronavirus, significantly greater than the estimated incidence in the local area.

Although patients admitted to NHS hospitals are now routinely screened for covid-19 and isolated if necessary, NHS workers are tested and excluded from work only if they develop symptoms of the illness.

Mike Weekes, the study's lead author, told The BMJ that in light of the findings this practice must change."Test, test, test, and test again. That's the absolute key," he said. "We need to test all staff as frequently as we possibly can, irrespective of symptoms, to prevent hospitals from becoming hubs of transmission."

Hospitals should be vigilant in ensuring that areas such as staff rooms don't become hubs for spreading infection because of the difficulty in enabling social distancing and the absence of PPE, Weekes said.

He said, "A lot of cases could be in staff rooms where it's more difficult to socially distance in an enclosed environment. It might be in lunch areas where people don't wear PPE. It might tell us that, for example, in all areas in the hospital everybody [all staff] should be wearing a mask at all times."

The BMJ asked NHS England for comment, but it had not replied in time for publication.

1 Bhanot SM, Agarwal M, Nair M, Bhushan R. BAME, the NHS and covid-19, where do we go from here? [electronic response to Rimmer A. Covid-19: Two thirds of healthcare workers who have died were from ethnic minorities]. BMJ 2020. https://www.bmj.com/ content/369/bmj.m1621/rr-0.

2 Harding L, Campbell D. Up to $20 \%$ of hospital patients with Covid- 19 caught it at hospital. Guardian. 17 May 2020. https://www.theguardian.com/world/2020/may/17/hospital-patientsengland-coronavirus-covid-19.

3 Johnson B. Covid-19: strategy. House of Commons official report (Hansard). 11 May 2020: col 24. https://hansard.parliament.uk/commons/2020-05-11/debates/D92692B5165B-4ACB-BC97-4C3F25D726EE/Covid-19Strategy.

4 Rivett L, Sridhar S, Sparkes D, etal. CITIID-NIHR COVID-19 BioResource Collaboration. Screening of healthcare workers for SARS-CoV-2 highlights the role of asymptomatic carriage in COVID-19 transmission. Elife 2020;9:e58728. 10.7554/eLife.58728 32392129 Published by the BMJ Publishing Group Limited. For permission to use (where not already granted under a licence) please go to http://group.bmj.com/group/rights-licensing/ permissions 